\title{
Rare adverse events associated with oral poliovirus vaccine in Brazil
}

F. Friedrich

\author{
Correspondence \\ F. Friedrich \\ Departamento de Virologia \\ Instituto Oswaldo Cruz, FIOCRUZ \\ 21040-360 Rio de Janeiro, RJ \\ Brasil \\ Fax: 55 (021) 270-6397
}

Research supported by the Panamerican Health Organization (Expanded Program on Immunization), CNPq and CAPES.

$\ldots \ldots \ldots \ldots \ldots \ldots \ldots$

Received January 17, 1997

Accepted April 22, 1997
Departamento de Virologia, Instituto Oswaldo Cruz, FIOCRUZ,

21040-360 Rio de Janeiro, RJ, Brasil

\begin{abstract}
Oral poliovirus vaccine (OPV) developed by A. Sabin has been effectively used to control poliomyelitis in Brazil, and the last case with the isolation of a wild poliovirus strain occurred in March 1989. Although the vaccine controlled the circulation of wild strains and poliomyelitis cases associated with these strains were not detected during the last eight years, rare cases classified as vaccine-associated paralytic poliomyelitis (VAPP) have been detected. Molecular characterization studies of poliovirus strains isolated from VAPP cases and from healthy contacts have confirmed that the isolates are derived from the Sabin vaccine strains and also detected genomic modifications known or suspected to increase neurovirulence such as mutations and recombination. The molecular characterization of polioviruses isolated during the last eight years from paralysis cases classified as Guillain-Barré (GBS) syndrome and transverse myelitits (TM), and from facial paralysis (FP) cases also confirmed the vaccine origin of the strains and demonstrated mutations known to increase neurovirulence. Analysis of the epidemiologic data of these GBS, TM and FP cases demonstrated that in most of them the last OPV dose was given months or years before the onset of the disease and the isolation of the polioviruses. The temporal association between the isolation of these strains and the GBS, TM and FP suggested that the Sabin vaccinederived poliovirus strains could also rarely trigger the diseases.
\end{abstract}

\section{Introduction}

Poliomyelitis, a paralytic and sometimes fatal disease of humans, is caused by poliovirus (1-3). The disease has been effectively controlled in many parts of the world by the use of two vaccines: the inactivated poliovirus vaccine (IPV) developed by Jonas Salk (4) and the oral poliovirus vaccine (OPV) developed by Albert Sabin $(1,2,5,6)$. OPV, the most widely used vaccine, consists of three attenuated poliovirus strains (Sabin 1, 2 and 3), one for each serotype. The three
Key words

- Poliovirus

- Poliomyelitis

- Guillain-Barré syndrome

- Tranverse myelitis

- Facial paralysis

- Vaccine-associated cases

...................... attenuated Sabin vaccine strains were all derived from wild-type isolates by serial passage in monkey tissue in vitro and in vivo under a variety of conditions, which differed for each of the three serotypes $(1,2)$. Mass immunization campaigns with OPV were a major factor influencing the success of eradication of wild indigenous poliovirus in Brazil and in the Americas. Although OPV is important in the control of poliomyelitis and in the circulation of wild strains, one disadvantage associated with OPV is the rare occurrence (5-8) of vaccine-associated paralyt- 
ic poliomyelitis (VAPP) cases. Rare VAPP cases occur mainly with the type 2 and 3 strains and less frequently with the type 1 strain. The larger number of attenuating mutations in the P1/Sabin strain is probably reflected by the higher safety of this strain in comparison to type 2 and 3 strains (8). Knowledge about the molecular basis of attenuation of vaccine strains and the mechanisms of reversion to neurovirulence (1-3,8-11) may allow rational improvement of vaccines and production methods, provide alternative models for vaccine safety tests on transgenic mice and/or molecular approaches (12-15), and avoid expensive safety testing of vaccine pools in primates.

\section{Poliomyelitis in Brazil and other countries}

An international effort is underway to eradicate poliomyelitis from the planet by the year 2000 (16). Surveillance for wild poliovirus circulation is crucial to this effort. Today, poliomyelitis is very rare in all developed and many developing countries $(17,18)$. Although the last poliomyelitis case with the isolation of wild indigenous poliovirus in the Americas occurred in Peru in August 1991 (17,19-21), poliomyelitis continues to be a serious threat to children in parts of Asia, Africa and Europe $(18,22)$. Molecular epidemiologic studies have been very important in poliovirus surveillance in several countries $(18,22-29)$, and have demonstrated that although the incidence of cases caused by wild polioviruses showed a major decline in the planet $(17,18)$ with the use of OPV, the circulation of wild strains continues in many regions.

Despite these worldwide impressive gains in the control and reduction of poliomyelitis cases associated with wild polioviruses, rare VAPP cases have been detected in several countries (30-39). Molecular epidemiologic studies have confirmed that the polioviruses isolated from these rare cases are derived from the Sabin vaccine strains, and also detected genomic modifications such as mutations and recombination $(38,40-61)$. Although reverting mutations in attenuating determinants, suppressor mutations, mutations in antigenic sites and genomic recombination have been observed in strains isolated from VAPP cases, the observation of similar genomic modifications in strains isolated from healthy vaccinees $(8,9,11,38,43$, $44,48-50,53,56,62-69)$ has supported the view that host factors are also involved in the establishment of the disease. Specific biochemical characteristics of host factor(s) involved in the replication of the virus in human cells may increase the replication level of the virus in certain patients (8). Host factors such as immune deficiency may also be involved in the establishment of the disease in certain cases, and may be related to heritable immunodeficiencies, immunodeficiencies caused by protein-calorie malnutrition, deficiency in vitamin A, or HIV infection $(7,33,34,39,70-75)$. Intramuscular injections within 30 days of exposure to OPV through vaccine or contact with a recent vaccinee might also be a risk factor for VAPP cases (76). Other host factors and other pathological conditions could also be involved.

OPV has also been efficiently used to control poliomyelitis in Brazil and the last case with the isolation of a wild poliovirus strain occurred in March 1989 (77). Molecular epidemiologic studies have been very important in poliovirus surveillance in our country (77-79). Isolation of polioviruses in cell cultures and characterization of the serotype using hyperimmune equine sera (80), molecular hybridization (81), PCR (82) and nucleotide sequencing $(23,83)$ have been important in the characterization of the isolated polioviruses. Although the Sabin vaccine strains have been efficiently used in the control of poliomyelitis in Brazil, rare VAPP cases still occur. Molecular biology studies have confirmed that the polioviruses isolated from these rare cases are derived from 
the Sabin vaccine strains (84-87), and have also detected genomic modifications known to increase neurovirulence.

\section{Genomic characterization of polioviruses isolated from vaccine-associated paralytic poliomyelitis cases in Brazil}

Polioviruses isolated from fecal samples from VAPP cases in Brazil were characterized as related to the Sabin vaccine strains by molecular hybridization and PCR $(77,84-$ 86). Partial sequencing of the genome of some of these strains confirmed the vaccine origin (84-87) and also demonstrated genomic modifications. Most of the strains isolated from VAPP cases presented mutations known to increase the neurovirulence $(84,85)$ and several strains proved to be recombinants (87). Vaccine/vaccine and vaccine/non-vaccine strains were identified among the recombinants isolated (87). Molecular studies of polioviruses isolated from fecal samples and from the central nervous system of VAPP cases in other countries have suggested that not only mutations, but also genomic recombination could increase the neurovirulence of the Sabin vaccine strains and/or provide some advantages for virus replication (38,52,54,57-60). Mutations known to increase neurovirulence and recombination have also been identified in the polioviruses isolated from healthy contacts of VAPP cases in Brazil $(84,87)$. Interestingly, the polioviruses isolated from VAPP cases and from their healthy contacts presented the same serotype, the same nucleotide sequences and the same mutations in the regions analyzed, confirming the transmission of the strains. The isolation of poliovirus strains from VAPP cases and from healthy contacts in Brazil presenting similar genomic modifications $(84,87)$, and known or suspected to increase neurovirulence, supports the idea that host factors are also involved in the establishment of poliomyelitis
$(8,84)$. Although some strains isolated from VAPP $(84,86)$ cases maintained important attenuating determinants, one possibility is that other mutations occurred in the partially sequenced genome, which were able to increase neurovirulence and/or provide some advantage for virus multiplication in the patient.

\section{Genomic characterization of polioviruses isolated from Guillain-Barré syndrome and from transverse myelitis cases in Brazil}

Some studies in other countries have suggested that paralysis observed during the Guillain-Barré syndrome and transverse myelitis might also be rarely triggered or caused by Sabin vaccine-derived poliovirus strains (88-90). Interestingly, several poliovirus strains were isolated (77) from fecal samples of paralysis cases in Brazil classified as Guillain-Barré syndrome (91) and transverse myelitis. Polioviruses isolated from these cases were characterized as related to the Sabin vaccine strains by molecular hybridization and PCR (77,85,92-94). Partial sequencing of the genome of some of these strains confirmed the vaccine origin and also demonstrated mutations known to increase neurovirulence $(85,92)$. Analysis of the epidemiological data for these cases demonstrated that in most of them the last Sabin vaccine dose was given months or years before the onset of the disease and the isolation of the polioviruses $(85,92-94)$. The temporal association between the isolation of these strains from fecal samples and the Guillain-Barré syndrome or transverse myelitis in Brazil suggested that the Sabin vaccine-derived poliovirus strains could also rarely trigger these diseases. In a recent publication (95) poliovirus type 3 was isolated from the brain tissues of a fatal GuillainBarré syndrome case observed in another country, and serodifferentiation of this poliovirus within the same type 3 showed a 
vaccine-like pattern. Poliovirus was detected in the cytoplasma of brain tissue and also in the intranuclear parts of ganglion and glia cells by an immunofluorescent technique.

\section{Genomic characterization of polioviruses isolated from facial paralysis cases in Brazil}

Among the several neurologic syndromes investigated by the Brazilian program for the eradication of poliomyelitis, with the objective of detecting wild poliovirus strains, peripheral facial paralysis was included until 1992 (96). Wild polioviruses were still isolated during the 1987-1989 period from fecal samples of facial paralysis cases (96). The isolation of wild strains from facial paralysis cases suggested that Sabin vaccinederived poliovirus strains could also rarely cause facial paralysis. The genome of some poliovirus strains isolated from fecal samples of facial paralysis cases and characterized by molecular hybridization and PCR as Sabin vaccine-related strains was partially sequenced $(85,92)$. Nucleotide sequence analysis confirmed the vaccine origin of the isolates and also identified mutations known to increase neurovirulence $(85,92)$. The temporal association between the isolation of these strains and the facial paralysis suggested that the Sabin vaccine strains could also, in rare cases, cause this disease.

\section{Discussion, conclusions and perspectives}

Molecular characterization studies of poliovirus strains isolated in Brazil from rare paralytic poliomyelitis cases and also from cases classified as Guillain-Barré syndrome, transverse myelitis and facial paralysis demonstrated that the isolates are derived from the Sabin vaccine strains $(77-79,84-87,92-$ 94 ), and that most of the isolates analyzed present genomic modifications known or suspected to increase neurovirulence $(78,79$,
$84,85,87,92)$. The temporal association between the isolation of these strains and the Guillain-Barré syndrome, transverse myelitis and facial paralysis in Brazil suggested that these diseases could also be triggered in rare cases by Sabin poliovirus vaccine strains. The isolation of polioviruses derived from the Sabin vaccine strains (and not from wild strains) from rare paralysis cases classified as poliomyelitis, Guillain-Barré syndrome, transverse myelitis and facial paralysis in Brazil during the last 7 years confirms the efficiency of the Sabin vaccine strains in the control of the circulation of wild poliovirus strains, but shows that rare adverse events are associated with the use of the oral poliovirus vaccine.

Since wild poliovirus is still endemic in many regions of the planet $(18,22)$, there is always the threat of importation of these strains from other countries. Although rare adverse events are associated with the use of OPV in Brazil, the circulation of wild strains in other countries demonstrates the importance and the need to maintain immunization against poliomyelitis. Since the Sabin vaccine strains may increase neurovirulence by genomic modifications during multiplication in the vaccinee and after transmission to contacts, there is also always the possibility of the appearance of neurovirulent strains derived from the Sabin vaccine strains $(8,9,11,38,42-44,46-60)$. Thus, these studies demonstrate that immunization is important not only to avoid the possibility of spreading imported wild strains, but also to control and prevent the possible transmission and circulation of Sabin vaccine-derived mutant strains with an increased neurovirulence for humans $(84,87)$.

Studies in other countries have demonstrated the capacity of Sabin vaccine-derived poliovirus strains to cause a persistent infection in human neuroblastoma cells (97); nucleotide sequence analysis demonstrated mutations in these strains $(98,99)$. More recent studies demonstrated that poliovirus 
can persistently infect primary cultures of human fetal brain cells (100). Several lines of evidence have suggested that polioviruses and other enteroviruses might cause a persistent infection in humans and chronic diseases of the central nervous system (101105). The isolation of polioviruses derived from the Sabin vaccine strains from patients presenting paralysis after the onset of motor deficiency and in which the last vaccine dose was given months or years before the onset of disease $(84,85,92-94)$ suggested transmission or a persistent infection. Although most poliovirus infections are silent (106), there is always the possibility of transmission of Sabin vaccine-derived strains to other individuals that may occasionally develop the disease (84). The transmission of Sabin vaccine-derived strains with many genomic modifications was confirmed by nucleotide sequencing of strains isolated from VAPP cases and from healthy contacts $(84,87)$.

It would also be interesting in the future to study the possibility of a persistent infection and excretion of Sabin vaccine-derived strains in Brazilian patients presenting poliomyelitis, post-polio syndrome, GuillainBarré syndrome, transverse myelitis, and facial paralysis, and also in healthy contacts and healthy vaccinees. Even if persistent infection and excretion of the vaccine strains are rare, they could lead to the excretion of polioviruses for long periods of time and to the possibility of the transmission of highly mutated strains to other individuals. Most polioviruses derived from the Sabin vaccine strains have been isolated from the stool of vaccine-associated cases and of healthy vaccinees (8). It would be interesting to study if genomic modifications able to increase neurovirulence, and detected in Sabin vaccinederived strains isolated from stool (and/or CNS) also occur during multiplication in the oropharynx of vaccinees. Although different host factors might also be involved in the establishment of the disease, it would be important to evaluate the immune status (71$75,84,95,107)$ of Brazilian patients presenting VAPP, Guillain-Barré syndrome, transverse myelitis and facial paralysis.

Recent studies in Brazil (108) have indicated the susceptibility of dogs to infection with human enteroviruses, including polioviruses. It would be interesting to infect dogs, or even transgenic mice $(109,110)$ susceptible to polioviruses by the oral route to study the possibility of infection and persistence of these viruses in other animals in nature, and to determine if genomic modifications known to increase neurovirulence also occur during multiplication of the Sabin vaccine strains in these animals, and if these viruses are eventually efficiently excreted.

These studies demonstrate that molecular epidemiologic studies on poliomyelitis and other paralytic diseases possibly also caused by polioviruses are still very important and could contribute to a better understanding of poliovirus biology and the rare adverse events associated with OPV, which could in turn help to eliminate or reduce these rare adverse events.

\section{Acknowledgments}

I thank Dr. H.G. Schatzmayr, Head of the Department of Virology, and Dr. Edson E. Da Silva, Head of the Enterovirus Laboratory of the Department of Virology, Instituto Oswaldo Cruz, for supporting my studies on vaccine-associated cases in Brazil. I thank A.M.B. Filippis, F.C. Ferreira, M.C. Costa, A.P. Santos and Suzana A. Chagas, Enterovirus Laboratory of the Department of Virology, for technical assistance and important contribution to these studies. I thank the Epidemiologists (Polio Group) from the Ministry of Health, Brazil, for sending highly useful information about the patients analyzed in these studies. 


\section{References}

1. Almond JW (1987). The attenuation of poliovirus neurovirulence. Annual Review of Microbiology, 41: 153-180.

2. Racaniello VR (1988). Poliovirus neurovirulence. Advances in Virus Research, 34: 217-246.

3. Wimmer E, Hellen CUT \& Cao X (1993). Genetics of poliovirus. Annual Review of Genetics, 27: 353-436.

4. Murdin AD, Barreto L \& Plotkin S (1996). Inactivated poliovirus vaccine: past and present experience. Vaccine, 14: 735-746.

5. Horaud F (1993). Albert B. Sabin and the development of oral poliovaccine. Biologicals, 21: 311-316.

6. Horaud F (1995). An historical outline of the development of live poliovaccine and its non-target effects. Developments in Biological Standardization, 84: 117-122.

7. World Health Organization (1982). The relation between acute persisting spinal paralysis and poliomyelitis vaccine - results of a ten-year enquiry. Bulletin of the World Health Organization, 60: 231-242.

8. Friedrich F (1996). Genomic modifications in Sabin vaccine strains isolated from vaccination-associated cases, healthy contacts and healthy vaccinees. Acta Virologica, 40: 157-170.

9. Minor PD (1992). The molecular biology of poliovaccines. Journal of General Virology, 73: 3065-3077.

10. Minor PD (1993). Attenuation and reversion of the Sabin vaccine strains of poliovirus. Developments in Biological Standardization, 78: 17-26.

11. Minor PD, Macadam AJ, Stone DM \& AImond JW (1993). Genetic basis of attenuation of the Sabin oral poliovirus vaccines. Biologicals, 21: 357-363.

12. Chumakov K, Norwood L, Parker M, Dragunsky E, Taffs R, Ran Y, Ridge J \& Levenbook I (1993). Assessment of the viral RNA sequence heterogeneity for control of OPV neurovirulence. Developments in Biological Standardization, 78: 79-89.

13. Dragunsky E, Taffs R, Chernokhvostova Y, Nomura T, Hioki K, Gardner D, Norwood L \& Levenbook I (1996). A poliovirus-susceptible transgenic mouse model as a possible replacement for the monkey neurovirulence test of oral poliovirus vaccine. Biologicals, 24: 77-86.
14. Lu Z, Rezapkin GV, Douthitt MP, Ran Y, Asher DM, Levenbook IS \& Chumakov KM (1996). Limited genetic changes in the Sabin 1 strain of poliovirus occurring in the central nervous system of monkeys. Journal of General Virology, 77: 273280.

15. Lu Z, Asher DM, Levenbook IS \& Chumakov KM (1996). Succession of mutations in the Sabin strain of type 3 poliovirus replicating in the central nervous system of monkeys. Virology, 220: 285-289.

16. Wright PF, Kim-Farley RJ, de-Quadros CA, Robertson SE, Scott RMN, Ward NA \& Henderson RH (1991). Strategies for the global eradication of poliomyelitis by the year 2000. New England Journal of Medicine, 325: 1774-1779.

17. Hull HF, Ward NA, Hull BP, Milstien JB \& de-Quadros C (1994). Paralytic poliomyelitis: seasoned strategies, disappearing disease. Lancet, 343: 1331-1337.

18. Kew OM, Mulders MN, Lipskaya GY, DaSilva EE \& Pallansch MA (1995). Molecular epidemiology of polioviruses. Seminars in Virology, 6: 401-414.

19. Centers for Disease Control (1992). Update: Eradication of paralytic poliomyelitis in the Americas. Morbidity and Mortality Weekly Report, 41: 681-683.

20. Centers for Disease Control and Prevention (1994). Certification of poliomyelitis eradication - the Americas, 1994. Morbidity and Mortality Weekly Report, 43: 720722.

21. World Health Organization (1994). Expanded programme on immunization. Certification of poliovirus eradication - the Americas. Weekly Epidemiological Record, 69: 293-295.

22. Mulders MN, Lipskaya GY, van-der-Avoort HGAM, Koopmans MPG, Kew OM \& vanLoon AM (1995). Molecular epidemiology of wild poliovirus type 1 in Europe, the Middle East, and the Indian subcontinent. Journal of Infectious Diseases, 171: 13991405.

23. Rico-Hesse R, Pallansch MA, Nottay BK \& Kew OM (1987). Geographic distribution of wild poliovirus type 1 genotypes. Virology, 160: 311-322.

24. Zheng DP, Zhang LB, Fang ZY, Yang CF, Mulders M, Pallansch MA \& Kew OM (1993). Distribution of wild type 1 poliovirus genotypes in China. Journal of Infectious Diseases, 168: 1361-1367.
25. Oostvogel PM, van-Wijngaarden JK, vander-Avoort HGAM, Mulders MN, Conynvan Spaendonck MAE, Rümke $H C$, vanSteenis G \& van-Loon AM (1994). Poliomyelitis outbreak in an unvaccinated community in the Netherlands, 1992-93. Lancet, 344: 665-670.

26. van-Niekerk $A B W$, Vries JB, Baard J, Schoub BD, Chezzi C \& Blackburn NK (1994). Outbreak of paralytic poliomyelitis in Namibia. Lancet, 344: 661-664.

27. Huovilainen A, Mulders MN, Agboatwalla M, Pöyry T, Stenvik M \& Hovi T (1995). Genetic divergence of poliovirus strains isolated in the Karachi region of Pakistan. Journal of General Virology, 76: 30793088.

28. Li J, Yoneyama T, Yoshida H, Yoshii K, Shimizu H, Miyamura T, Hara M, Hou XH, Zheng $\mathrm{H}$, Fang $\mathrm{Y}$, Zhang LB \& Hagiwara A (1995). Genetic analysis of wild-type 1 poliovirus isolates in China, 1985-1993. Research in Virology, 146: 415-422.

29. Lipskaya GY, Chervonskaya EA, Belova GI, Maslova SV, Kutateladze TN, Drozdov SG, Mulders M, Pallansch MA, Kew OM \& Agol VI (1995). Geographical genotypes (geotypes) of poliovirus case isolates from the former Soviet Union: relatedness to other known poliovirus genotypes. Journal of General Virology, 76: 1687-1699.

30. Schonberger LB, McGowan JE \& Gregg MB (1976). Vaccine-associated poliomyelitis in the United States, 1961-1972. American Journal of Epidemiology, 104: 202-211.

31. Basilico FC \& Bernat JL (1978). Vaccineassociated poliomyelitis in a contact. Journal of the American Medical Association, 239: 2275.

32. Maas G \& Quast U (1987). Acute spinal paralysis after the administration of oral poliomyelitis vaccine in the Federal Republic of Germany (1963-1984). Journal of Biological Standardization, 15: 185-191.

33. Nkowane BM, Wassilak SGF, Orenstein WA, Bart KJ, Schonberger LB, Hinman AR \& Kew OM (1987). Vaccine-associated paralytic poliomyelitis in the United States: 1973 through 1984. Journal of the American Medical Association, 257: 13351340.

34. Joce $R$, Wood D, Brown D \& Begg $N$ (1992). Paralytic poliomyelitis in England and Wales, 1985-91. British Medical Journal, 305: 79-82. 
35. Strebel PM, Sutter RW, Cochi SL, Biellik RJ, Brink EW, Kew OM, Pallansch MA, Orenstein WA \& Hinman AR (1992). Epidemiology of poliomyelitis in the United States one decade after the last report case of indigenous wild virus-associated disease. Clinical Infectious Diseases, 14: 568-579.

36. Strebel PM, Aubert-Combiescu A, IonNedelcu N, Biberi-Moroeanu S, Combiescu M, Sutter RW, Kew OM, Pallansch MA, Patriarca PA \& Cochi SL (1994). Paralytic poliomyelitis in Romania, 1984-1992: Evidence for a high risk of vaccine-associated disease and reintroduction of wild-virus infection. American Journal of Epidemiology, 140: 1111-1124.

37. Andrus JK, Strebel PM, de-Quadros CA \& Olivé JM (1995). Risk of vaccine-associated paralytic poliomyelitis in Latin America, 1989-91. Bulletin of the World Health Organization, 73: 33-40.

38. Driesel G, Diedrich S, Künkel U \& Schreier E (1995). Vaccine-associated cases of poliomyelitis over a 30 year period in East Germany. European Journal of Epidemiology, 11: 1-8.

39. Centers for Disease Control and Prevention (1997). Paralytic poliomyelitis - United States, 1980-1994. Journal of the American Medical Association, 277: 525-526.

40. Kew OM, Nottay BK, Hatch MH, Nakano JH \& Obikeski JF (1981). Multiple genetic changes can occur in the oral poliovaccines upon replication in humans. Journal of General Virology, 56: 337-347.

41. Minor PD (1982). Characterization of strains of type 3 poliovirus by oligonucleotide mapping. Journal of General Virology, 59: 307-317.

42. Cann AJ, Stanway G, Hughes PJ, Minor PD, Evans DMA, Schild GC \& Almond JW (1984). Reversion to neurovirulence of the live-attenuated Sabin type 3 oral poliovirus vaccine. Nucleic Acids Research, 12: 7787-7792.

43. Almond JW, Westrop GD, Cann AJ, Stanway G, Evans DMA, Minor PD \& Schild GC (1985). Attenuation and reversion to neurovirulence of the Sabin poliovirus type 3 vaccine. In: Lerner RA, Chanock RM \& Brown $F$ (Editors), Vaccines 85. Cold Spring Harbor Laboratory, New York, 271-277.

44. Evans DMA, Dunn G, Minor PD, Schild GC, Cann AJ, Stanway G, Almond JW, Currey K \& Maizel Jr JV (1985). Increased neurovirulence associated with a single nucleotide change in a noncoding region of the Sabin type 3 poliovaccine genome. Nature, 314: 548-550.
45. Fiore L, Pierangeli A, Lombardi F, Santoro $R$, Crainic R, Venuti A \& Perez-Bercoff $R$ (1987). Antigenic and biochemical characterization of poliovirus type 2 isolated from two cases of paralytic disease. Intervirology, 27: 196-204.

46. Minor PD, Dunn G, Evans DMA, Magrath DI, John A, Howlett J, Phillips A, Westrop G, Wareham K, Almond JW \& Hogle JM (1989). The temperature sensitivity of the Sabin type 3 vaccine strain of poliovirus: molecular and structural effects of a mutation in the capsid protein VP3. Journal of General Virology, 70: 1117-1123.

47. Pollard SR, Dunn G, Cammack N, Minor PD \& Almond JW (1989). Nucleotide sequence of a neurovirulent variant of the type 2 oral poliovirus vaccine. Journal of Virology, 63: 4949-4951.

48. Macadam AJ, Arnold C, Howlett J, John A, Marsden S, Taffs F, Reeve P, Hamada $\mathrm{N}$, Wareham K, Almond J, Cammack N \& Minor PD (1989). Reversion of the attenuated and temperature-sensitive phenotypes of the Sabin type 3 strain of poliovirus in vaccinees. Virology, 172: 408-414.

49. Macadam AJ, Pollard SR, Ferguson G, Dunn G, Skuce R, Almond JW \& Minor PD (1991). The 5 ' noncoding region of the type 2 poliovirus vaccine strain contains determinants of attenuation and temperature sensitivity. Virology, 181: 451-458.

50. Macadam AJ, Pollard SR, Ferguson G, Skuce R, Wood D, Almond JW \& Minor PD (1993). Genetic basis of attenuation of the Sabin type 2 vaccine strain of poliovirus in primates. Virology, 192: 18-26.

51. Equestre M, Genovese D, Cavaliere F, Fiore L, Santoro R \& Perez-Bercoff $R$ (1991). Identification of a consistent pattern of mutations in neurovirulent variants derived from the Sabin vaccine strain of poliovirus type 2. Journal of Virology, 65 : 2707-2710.

52. Lipskaya GY, Muzychenko AR, Kutitova OK, Maslova SV, Equestre M, Drozdov SG, Perez-Bercoff R \& Agol VI (1991). Frequent isolation of intertypic poliovirus recombinants with serotype 2 specificity from vaccine-associated polio cases. Journal of Medical Virology, 35: 290-296.

53. Muzychenko AR, Lipskaya GY, Maslova SV, Svitkin YV, Pilipenko EV, Nottay BK, Kew OM \& Agol VI (1991). Coupled mutations in the $5^{\prime}$-untranslated region of the Sabin poliovirus strains during in vivo passages: structural and functional implications. Virus Research, 21: 111-122.
54. Furione $M$, Guillot $S$, Otelea D, Balanant J, Candrea A \& Crainic R (1993). Poliovirus with natural recombinant genomes isolated from vaccine-associated paralytic poliomyelitis. Virology, 196: 199-208.

55. Otelea D, Guillot S, Furione M, Combiescu AA, Balanant J, Candrea A \& Crainic R (1993). Genomic modifications in naturally occurring neurovirulent revertants of Sabin 1 polioviruses. Developments in Biological Standardization, 78: 33-38.

56. Guillot $S$, Otelea D, Delpeyroux F \& Crainic $R$ (1994). Point mutations involved in the attenuation/neurovirulence alternation in type 1 and 2 oral polio vaccine strains detected by site-specific polymerase chain reaction. Vaccine, 12: 503-507.

57. Georgescu MM, Delpeyroux F, TardyPanit M, Balanant J, Combiescu M, Combiescu AA, Guillot S \& Crainic R (1994). High diversity of poliovirus strains isolated from the central nervous system from patients with vaccine-associated paralytic poliomyelitis. Journal of Virology, 68: 8089-8101.

58. Georgescu MM, Delpeyroux F \& Crainic R (1995). Tripartite genome organization of a natural type 2 vaccine/nonvaccine recombinant poliovirus. Journal of General Virology, 76: 2343-2348.

59. Georgescu MM, Tardy-Panit M, Guillot S, Crainic R \& Delpeyroux F (1995). Mapping of mutations contributing to the temperature sensitivity of the Sabin 1 vaccine strain of poliovirus. Journal of Virology, 69: 5278-5286.

60. Li J, Zhang LB, Yoneyama T, Yoshida H, Shimizu H, Yoshii K, Hara M, Nomura T, Yoshikura $H$, Miyamura $T$ \& Hagiwara $A$ (1996). Genetic basis of the neurovirulence of type 1 polioviruses isolated from vaccine-associated paralytic patients. Archives of Virology, 141: 1047-1054.

61. Jiming Z (1996). Comments on some new viruses associated with old diseases in China. Chinese Medical Journal, 109: 510.

62. Minor PD, John A, Ferguson M \& Icenogle JP (1986). Antigenic and molecular evolution of the vaccine strain of type 3 poliovirus during the period of excretion by a primary vaccinee. Journal of General Virology, 67: 693-706.

63. Cammack N, Phillips A, Dunn G, Patel V \& Minor PD (1988). Intertypic genomic rearrangements of poliovirus strains in vaccinees. Virology, 167: 507-514. 
64. Minor PD \& Dunn G (1988). The effect of sequences in the 5 'noncoding region on the replication of polioviruses in the human gut. Journal of General Virology, 69: 1091-1096.

65. Dunn G, Begg NT, Cammack N \& Minor PD (1990). Virus excretion and mutation by infants following primary vaccination with live oral poliovaccine from two sources. Journal of Medical Virology, 32: 92-95.

66. Ogra PL, Faden HS, Abraham R, Duffy LC, Sun M \& Minor PD (1991). Effect of prior immunity on the shedding of virulent revertant virus in faeces after oral immunization with live attenuated poliovirus vaccines. Journal of Infectious Diseases, 164: 191-194.

67. Tatem JM, Weeks-Levy C, Mento SJ, DiMichele SJ, Georgiu A, Waterfield WF, Sheip B, Costalas C, Davies T, Ritchey MB \& Cano FR (1991). Oral poliovirus vaccine in the United States: molecular characterization of Sabin type 3 after replication in the gut of vaccinees. Journal of Medical Virology, 35: 101-109.

68. Contreras G, Dimock K, Furesz J, Gardell C, Hazlett D, Karpinski K, McCorkle G \& Wu L (1992). Genetic characterization of Sabin types 1 and 3 poliovaccine virus following serial passage in the human intestinal tract. Biologicals, 20: 15-26.

69. Abraham R, Minor P, Dunn G, Modlin JF \& Ogra PL (1993). Shedding of virulent poliovirus revertants during immunization with oral poliovirus vaccine after prior immunization with inactivated polio vaccine. Journal of Infectious Diseases, 168: 11051109.

70. Lederman HM \& Winkelstein JA (1985). $X$-Linked agammaglobulinemia: an analysis of 96 patients. Medicine, 64: 145-156.

71. Arya SC (1994). Vaccine-associated poliomyelitis. Lancet, 343: 610-611.

72. Groom SN, Clewley J, Litton PA \& Brown DW (1994). Vaccine-associated poliomyelitis. Lancet, 343: 609-610.

73. Ion-Nedelcu N, Dobrescu A, Strebel PM \& Sutter RW (1994). Vaccine-associated paralytic poliomyelitis and HIV infection. Lancet, 343: 51-52.

74. Wyatt HV (1994). Vaccine-associated poliomyelitis. Lancet, 343: 610.

75. Zuckerman MA, Brink NS, Kyi M \& Tedder RS (1994). Exposure of immunocompromised individuals to health-care workers immunized with oral poliovaccine. Lancet, 343: 985-986.
76. Strebel PM, Ion-Nedelcu N, Baughman AL, Sutter RW \& Cochi SL (1995). Intramuscular injections within 30 days of immunization with oral poliovirus vaccine risk factor for vaccine-associated paralytic poliomyelitis. New England Journal of Medicine, 332: 500-506

77. Filippis AMB, Schatzmayr HG, Ferreira FC, Chagas SAR, Costa MC, Santos AP \& DaSilva EE (1994). Intratypic differentiation of polioviruses isolated from suspected cases of poliomyelitis in Brazil during the period of 1990 to 1993. Memorias do Instituto Oswaldo Cruz, 89: 513-518.

78. Friedrich F (1993). Caracterização genômica de amostras de poliovírus tipos 2 e 3 isoladas de casos de poliomielite paralítica associados a vacina Sabin no Brasil. Master's thesis. IOC/FIOCRUZ.

79. Friedrich F (1996). Modificações genô-micas em poliovírus tipos 1, 2 e 3 derivados da vacina Sabin, isolados no Brasil. Doctoral thesis. IOC/FIOCRUZ.

80. World Health Organization (1990). Manual for Virological Investigation of Poliomyelitis. WHO/EPI/CDS/POLIO/90.1.

81. Da-Silva EE, Pallansch MA, Holloway BP, Oliveira MJC, Schatzmayr HG \& Kew OM (1991). Oligonucleotide probes for the specific detection of the wild poliovirus types 1 and 3 endemic to Brazil. Intervirology, 32: 149-159.

82. Yang $\mathrm{CF}, \mathrm{De} \mathrm{L}$, Holloway BP, Pallansch MA \& Kew OM (1991). Detection and identification of vaccine-related polioviruses by the polymerase chain reaction. Virus Research, 20: 159-179.

83. Da-Silva EE, Schatzmayr HG \& Kew OM (1990). Nucleotide sequences of the VP1 capsid proteins of wild poliovirus types 1 and 3 from epidemic areas of Brazil. Brazilian Journal of Medical and Biological Research, 23: 1-5.

84. Friedrich F, Filippis AMB, Ferreira FC, Schatzmayr HG \& Da-Silva EE (1995). Genomic characterization of type 2 polioviruses isolated from vaccine-associated cases in Brazil. Brazilian Journal of Medical and Biological Research, 28: 733-742.

85. Friedrich F, Filippis AMB, Ferreira FC, Schatzmayr HG \& Da-Silva EE (1995). Genomic characterization of type 3 polioviruses isolated from vaccine-associated poliomyelitis cases in Brazil. Brazilian Journal of Medical and Biological Research, 28: 195-200.
86. Friedrich F, Filippis AMB, Ferreira FC, Oliveira MJC, Schatzmayr HG \& Da-Silva EE (1996). Poliovirus type 1 isolated from a vaccine-associated case of paralytic poliomyelitis in Brazil. Brazilian Journal of Medical and Biological Research, 29: 1518.

87. Friedrich F, Da-Silva EE \& Schatzmayr HG (1996). Type 2 poliovirus recombinants isolated from vaccine-associated cases and from healthy contacts in Brazil. Acta Virologica, 40: 27-33.

88. Kinnunen E, Färkkilä $M$, Hovi $T$, Juntunen J \& Weckström P (1989). Incidence of Guillain-Barré syndrome during a nationwide oral poliovirus vaccine campaign. Neurology, 39: 1034-1036.

89. Uhari M, Rantala H \& Niemelä M (1989). Cluster of childhood Guillain-Barré cases after an oral poliovaccine campaign. Lancet, 2: 440-441.

90. Stratton KR, Howe CJ \& Johnston RB (1994). Adverse events associated with childhood vaccines other than pertussis and rubella. Journal of the American Medical Association, 271: 1602-1605.

91. Poliomielite: Informe Semanal, ano VI $n^{\circ}$ 19 (1991). Ministério da Saúde, Brasília, DF.

92. Friedrich F, Filippis $A M B$, Ferreira FC, Schatzmayr HG \& Da-Silva EE (1995). Genomic characterization of type 1 Sabinrelated polioviruses isolated in Brazil. Acta Virologica, 39: 23-29.

93. Friedrich F, Filippis AMB \& Schatzmayr HG (1995). Sabin-related poliovirus vaccine strains isolated from transverse myelitis cases in Brazil. Revista do Instituto de Medicina Tropical de São Paulo, 37: 543-545.

94. Friedrich F, Filippis AMB \& Schatzmayr HG (1996). Temporal association between the isolation of Sabin-related poliovirus vaccine strains and the Guillain-Barré syndrome. Revista do Instituto de Medicina Tropical de São Paulo, 38: 55-58.

95. Ehrengut W (1996). Relationship of oral poliovirus vaccine administration to Guillain-Barré syndrome. Acta Paediatrica Japonica, 38: 423.

96. Poliomielite: Informe Semanal ano VI No. 33 (1991). Ministério da Saúde, Brasília, DF.

97. Colbère-Garapin F, Christodoulou C, Crainic R \& Pelletier I (1989). Persistent poliovirus infection of human neuroblastoma cells. Proceedings of the National Academy of Sciences, USA, 86: 75907594. 
98. Pelletier I, Couderc T, Borzakian S, Wyckoff E, Crainic R, Ehrenfeld E \& Colbère-Garapin $F$ (1991). Characterization of persistent poliovirus mutants selected in human neuroblastoma cells. $\mathrm{Vi-}$ rology, 180: 729-737.

99. Borzakian S, Pelletier I, Calvez V \& Colbère-Garapin F (1993). Precise missense and silent point mutations are fixed in the genomes of poliovirus mutants from persistently infected cells. Journal of Virology, 67: 2914-2917.

100. Pavio N, Buc-Caron MH \& ColbèreGarapin F (1996). Persistent poliovirus infection of human fetal brain cells. Journal of Virology, 70: 6395-6401.

101. Muir P \& Archard LC (1994). There is evidence for persistent enterovirus infections in chronic medical conditions in humans. Reviews in Medical Virology, 4 245-250.

102. Muir $P$, Nicholson F, Sharief MK, Thompson EJ, Cairns NJ, Lantos P, Spencer GT, Kaminski HJ \& Banatvala JE (1995). Evidence for persistent enterovirus infection of the central nervous system in patients with previous paralytic poliomyelitis. Annals of the New York Academy of Sciences, 753: 219-232.
103. Johnson RT (1995). Pathogenesis of poliovirus infections. Annals of the New York Academy of Sciences, 753: 361365.

104. Leon-Monzon ME \& Dalakas MC (1995). Detection of poliovirus antibodies and poliovirus genome in patients with the postpolio syndrome. Annals of the New York Academy of Sciences, 753: 208-218.

105. Leparc-Goffart I, Julien J, Fuchs F, Janatova I, Aymard M \& Kopecka H (1996). Evidence of presence of poliovirus genomic sequences in cerebrospinal fluid from patients with post-polio syndrome. Journal of Clinical Microbiology, 34: 2023-2026.

106. Eichner M \& Dietz K (1996). Eradication of poliomyelitis: When can one be sure that poliovirus transmission has been terminated? American Journal of Epidemiology, 143: 816-822.

107. Castrignano SB (1996). Resposta de portadores de deficiência de IgA à vacina oral contra a poliomielite: avaliação clínica e análise laboratorial da produção de anticorpos séricos e secretórios. Doctoral thesis. Medicina/USP.
108. Waldman EA, Moreira RC, Saez SG, Souza DFC, Carmona RCC, Takimoto S \& Cortes VA (1996). Human enterovirus infection in stray dogs. Some aspects of interest to Public Health. Revista do Instituto de Medicina Tropical de São Paulo, 38: 157-161.

109. Koike S, Horie H, Sato $Y$, Ise I, Taya C, Nomura T, Yoshioka I, Yonekawa H \& Nomoto A (1993). Poliovirus-sensitive transgenic mice as a new animal model. Developments in Biological Standardization, 78: 101-107.

110. Racaniello VR, Ren $R$ \& Bouchard $M$ (1993). Poliovirus attenuation and pathogenesis in a transgenic mouse model for poliomyelitis. Developments in Biological Standardization, 78: 109-116. 